\title{
The Pragmatics of Audiovisual Translation: \\ Voices from within in film subtitling
}

\section{Introduction}

Film subtitles are a distinctive instantiation of cinematic discourse, and a distinctive form of translation. As written interlingual representations of source dialogues that are themselves intralingual representations of naturally occurring speech, they are a double fiction. Like their source, they are subject to the double-layerness of filmic dialogue, and resulting tensions between the horizontal diegetic plane, i.e. of communication between characters on screen, and the vertical plane, i.e. of communication with audience recipients (Messerli 2017). And, critically, the enduring co-presence of source and target input in the multimodal film context generates a range of intersecting source/target frames of reference and interpretation for audiences. These features alone make language choices in subtitling unique, linguistically, pragmatically and socio-culturally, in terms both of production and reception (Guillot 2016a). Medium-related factors like space, time or readability and the reduction strategies they call for are additional challenges and sources of pragmatic idiosyncrasy for this form of translation. Together they make subtitling specific as an expressive mode, with a capacity to set its own conventions for representation from within and index pragmatic value in distinct ways. This has been shown for communicative practices like greetings, pronominal address or features like orality, for example, hitherto only within single pairs of languages (English/ttalian in Bruti, 2009, French/English in Guillot, 2010, English/Swedish in Meister, 2016, for example).

In this article, the representational potential of subtitling is approached comparatively across different languages. The study presented has two objectives. The first is to further the enquiry into subtitling's distinctive meaning potential, and the specific expressive capacity that it derives from the close interplay of modedriven practices like stylization or internal indexing, and of language-specific lexical, syntactic and pragmatic resources. The second is to begin exploring how different languages may harness their respective expressive capacities to subtitle representation, with a pilot case study across Romance and Germanic languages. The study is tentative at this stage, but part of a broader agenda to build our understanding of audiovisual translation (AVT) as intercultural mediation, and, ultimately, its societal impact.

The work has drawn on (Romance) French, Italian, Spanish and (Germanic) English and German subtitle data, all from Lonergan's 2016 feature film in US English Manchester by the Sea (MBS). Representation of source dialogues is explored qualitatively across these languages from a broad cross-cultural pragmatics perspective, in a subset of scenes from across the film.

Section 2 below contextualizes the project, at the interface of AVT studies and cross-cultural pragmatics. Data and methodology are covered in Section 3, together with preliminary observations from an earlier part of the study. Section 4 provides a sampling case study of a subset of features in their interplay, with particular focus on functional pragmatic markers, before concluding comments in final Section 5. 


\section{Background}

Audiovisual Translation (AVT) has shifted its grounds substantially since its early days as a new field of research in the mid-90s. It was then striving to find a place in Translation Studies, and to document main concerns and constraints across its various modes, from subtitling and dubbing to audio-description and others, to categorize issues and to typologize strategies for dealing with them in their multimodal host contexts. It has since expanded its disciplinary horizons: it has a growing presence in pragmatics and intercultural communication, evidenced in recent special issues of research journals or critical textbooks (Gambier and Ramos Pinto, 2016; Locher and Jucker, 2017; Pérez-González, 2018; Tipton and Desilla, 2018; Guillot, Pavesi and Desilla, 2019; Ranzato and Zanotti, 2018). There are now also more studies with a declared pragmatics stance, focusing on communicative practices or others aspects of language in use (e.g. (im)politeness, taboo language, dialects, language impairments) (Bruti and Zanotti, 2016; de Pablos-Ortega, 2019; Ghia, 2019; Meister, 2016; Pavesi and Formentelli, 2019 for recent examples). With this broadening of its disciplinary base, AVT has been able to diversify its methodological toolkit, an essential step in addressing the challenges, for research, of the massive growth in the volume of cultural artefacts mediated via AVT in both mainstream and amateur practices, as a consequence of digitization and global media dissemination. It is too early to tell how this unprecedented exposure to cultural otherness via AVT may affect the millions of daily regular consumers across the world, and their intercultural literacy. What is, in the end, AVT's cross- or intercultural pragmatic imprint on its publics? This is a key question for pragmatics, and a crucial incentive, for pragmatics, to share further its expertise with AVT research, from different angles. What is at stake is briefly synthesized below for mainstream film subtitling, from a translation studies and cross/intercultural pragmatics angle. The overlapping frames of reference that AVT activates, crossand interculturally, are central to the discussion. They are considered below at three levels of interdependence: text in the original language, translation, processing via the target language.

How does subtitling, a written mode of expression, simulate the fictional speech of source dialogues interlingually, under very special conditions: there is little space and time to play with (36-40 characters and one to six seconds per line); audiences have limited time to read the text showcased and process it in its fragmented subtitle-by-subtitle sequential presentation; the oddly culturally asynchronic context of reception makes it difficult to assess viewer's inferencing capacities, even before the range of their likely sociocultural profiles is taken into account. Space, time and line-by-line display are well documented as standard features affecting AVT (see Díaz Cintas and Remael, 2007, inter alia). Other aspects have yet to be. They include the (linguistic and cognitive) dynamic between the diegetic and extra-diegetic in AVT, in the complex cross- and intercultural ramifications of their inescapably dual relationship.

The extradiegetic plane is the third in an intricate architecture of interdependence between types and levels of engagement in AVT, at the interface of the inter- and the cross-cultural (Pavesi, in Guillot and Pavesi, 2019:499). With this third level, the focus shifts from original text embedded in a source language and culture, at the first (diegetic) level (e.g. French and France), to audiences watching scenes and actions enacted still within the source culture, but in a target language bringing with it different pragmatic expectations and frames of reference (e.g. for 
politeness in English, or communicative practices more broadly - address, greetings, taboo language, dialects, etc.). That is all largely a matter reception. To date, we know little of the impact on audience responses of this interplay of different expectations and frames of reference. What is at stake is how sense is made, from text with a meaning capacity modulated by the multisemiotic and multimodal filmic context, and in which subtitles are just one of a range of communicative instruments. Accounting for their interactions calls for reconceptualisations of subtitling and other AVT modes as communicative agents, within the broader participation structures of reception. This has been championed by Messerli, with appeals to evolve participation frameworks for different subtypes of fictional discourse, including cinematic discourse and, beyond that, subtitled cinematic discourse and its interlingual representations (Messerli, 2017, 2019). Empirical input from new technologies has, for its part, given us a much better picture of psycholinguistic processes of reception (eye trackers, ECG or EEGs; reading practices, the impact of subtitle segmentation, reactions to metaphor etc.; see Díaz Cintas and Szarkowska, 2020 (Eds) for current developments). But different work is needed to establish what drives audiences' responses to AVT from the pragmatics of fiction perspective represented in Messerli, and integrate it into AVT research. Doing so is critical if we are to unravel the processes that underpin interlingual mediation via AVT and its possible impact on intercultural literacy.

Understanding AVT as intercultural mediation is also closely dependent, in the first instance, on more systematic description of what happens in between, at the second level, of representation in text. At that level, culturally entrenched source text is re-articulated in a different language for audiences of a target culture, in a one-way process that engages translators' own interpretative frames and cross-cultural comparisons (Guillot and Pavesi, 2019:499). In all this, the enduring interactive cooccurrence of source and target input, and its bearing on audiences, adds another layer of representational complexity. Together with medium constraints, this inescapable co-presence makes AVT pragmatically distinctive in quite a unique way, beyond what has been shown for other media or genres, by Sidiropoulou, for example. With analyses of multimedia web articles in Greek and English, Sidiropoulou shows in this volume how shifts in accompanying visual elements affect inference-drawing mechanisms. She finds similar phenomena in (public) representations through translation in power-sensitive written political genres (journalistic and political academic discourse), where they are induced by text-based translation shifts in the written discourse (Sidiropoulou, 2013). Unlike those in AVT, the shifts here engage audiences neither in the continuously interactive process of responding to target texts in relation to source, nor in the vertical dynamics of film discourse and habituation to representational conventions set from within for the text.

Recent AVT studies with a declared (cross-cultural) pragmatics approach have been building up evidence of interesting phenomena at the second-level of target text representation, with implications for third-level engagement: hybridization processes, for example, documented by Pavesi and Formentelli (2019) for dubbing from English to Italian in representations of impoliteness via insults; or, in Ghia (2019), the autonomy of dubbed dialogues in the selection of specific linguistic markers to re-portray interpersonal relationships in target linguacultures, with application to pragmatic questions, also for English/Italian. The staging of impoliteness in English to Italian dubbing in instantiations mid-way between source language patterns and target language trait are thus shown in Pavesi and Formentelli to play to different inferencing frames, so allowing the source to 'shine 
through' the target in the process and convey insights into the patterns represented in original films.

There is a close connection in these findings, from corpus work in both instances, with the vertical indexing processes identified in case study work for subtitling. In earlier work, representational conventions are thus shown to be set up from within, with integrated interplay of language and form features. This has been observed across across a range of communicative practices (e.g. greetings, pronominal address or phone routines; Guillot, 2010, 2016b), and, more recently, taboo language (Guillot, 2019), as recapitulated briefly in the next section.

With these kinds of study, the focus has shifted from widespread concern for 'loss' in early AVT typologizing and contrastive research, to the distinctiveness and creative potential of AVT cinematic discourse as a meaning-making mode and language variety in its own right, with an in-built capacity to flag linguistic otherness. The representational challenges of linguistic and cultural mismappings for AVT are not, in other words, considered in terms of what interlingual mediation does not do, and indeed cannot do under constrained AVT conditions. The focus is instead on what AVT can do and does, on the creative opportunities that constrained conditions and language mismappings produce, on two fronts: for expression via interlanguage mediation; and for keeping viewers alert to linguistic otherness by the same token, in line with the kinds of phenomenon documented by Locher in this volume for Korean and relational work in amateur subtitling.

In the study discussed here, of subtitling in Lonergan's 2016 feature film Manchester by the Sea, this stance is applied prospectively to the potential for representation of different (types of) languages, in the second stage of exploratory work with the two related objectives outlined in the introduction: to further ongoing enquiry into the distinctiveness and creativity of subtitling as a mode of expression; and to make a start on inspecting how different languages may harness their own specificities to the demands and opportunities of interlingual subtitling.

Data, methodology and first stage insights are summarized next as a platform for the sampling discussion of data in Section 4, through the lens of functional pragmatic markers (FPMs), with brief reference to other points of interest identified in the data, e.g. T/V pronominal address.

These are vast topics in their own right, for naturally occurring speech and fictional discourse, let alone, as here, in interlingual oral-to-written representations in constrained culturally a-synchronic environment. They can only be dealt with as initial forays into their complexities, a way of setting the scene for more systematic enquiry.

\section{Data, methodology, first phase insights}

\subsection{Data and methodology}

Lonergan's 2016's Manchester by the Sea (MBS) is one of comparatively few films featuring subtitles in English, French, German, Italian and Spanish all on a single DVD, for the version released for the French language market, with transcriptions also available online, albeit sometimes in different versions. The data for the study is comprised of subtitle transcripts for these five languages, the MBS screenplay in English and source dialogues (SD) transcriptions for examples. The film takes up the story of a broken man, Lee Chandler, on his reluctant return to his home town of Manchester by the Sea in the US, the scene of an unspeakable tragedy that spelled 
the breakdown of his marriage (to Randi) a few years before, and a shift in his behaviour from happy and loving father of three to near sociopath, withdrawn and surly. His return is prompted by his brother Joe's untimely death, and his ensuing reluctant guardianship of Patrick, his nephew. The reasons and consequences for Lee of the dramatic event that destroyed him and his past life, a fire that lost him his home and his children, are disclosed gradually in flashbacks throughout the narrative.

The study has drawn on the four scenes identified below, selected for qualitative comparative analysis for two main reasons. They involve different types of interaction (dialogue/monologue; adults/children/family/other; jovial/sullen; with taboo/non-taboo language, etc.), and thus provide scope for different types of linguistic and pragmatic observation. They are taken from different points in the film, so that vertical textual indexing and development can be observed, if present: first scene post-credits (1), middle (2 and 3 ) and near-end (4), as shown below together with functions in the narrative:

$\begin{array}{ll}\text { Extract } 1 & {[00: 03: 48-00: 08: 37] \text { Lee's interactions as a handyman with }} \\ & \text { tenants of the apartment block in which he has been assisting } \\ & \text { with repairs; } \\ \text { Extract } 2 & {[00: 59: 43-01: 03: 04] \text { Lee's near monologic account of the fire }} \\ & \text { tragedy to the police. } \\ \text { Extract } 3 & {[01: 04: 11-01: 07: 48] \text { Lee, Patrick and (close friend of the family) }} \\ & \text { George's exchange about what to do with Joe's fishing boat } \\ & \text { (Patrick wants to keep it, Lee is unwilling) } \\ \text { Extract } 4 & \text { [01:54:56-01:58:36] Lee/Randi emotionally charged exchange } \\ & \text { during an unexpected encounter, their first since Lee's return. }\end{array}$

At this stage, the research is in the form of a small-scale qualitative case study, to capture the intricacies of representation in its manifestations across different languages, in an exploratory bottom-up diagnostic mode. Analyses focus initially on French and English, and extend then to German, Italian and Spanish.

First phase insights are outlined below. For reasons of space, and because the features identified are an intrinsic by-product of frame-by-frame subtitle display, most will be illustrated later in Section 4 where the analysis of the extracts is presented. These features are part and parcel of meaning-making throughout.

\subsection{First phase insights}

The study so far has confirmed the specificity of subtitling as an expressive mode, with distinctive attributes and strategies that transcend linguistic difference, but affect language choices, and their impact.

The form imposed by frame-by-frame line presentation in short segments is a primary drive behind this expressive idiosyncrasy. Associated constraints make reduction largely inescapable, which in turns affects linguistic choice. So does the combined impact of line segmentation and distribution across frames, and use of typographical conventions across languages. Line distribution across frames affects turn-taking, for instance, and characterization, as noted in Remael (2003) and PérezGonzález (2007), though largely overlooked subsequently. The impact of line distribution is clearly in evidence in the MBS data for this and other aspects, including the function of pragmatic markers considered in Section 4. 
These resources are used differentially across the languages in the MBS dataset, however, and not to the same extent. French streamlines text to the full, even where reduction is not called for. It accrues expressivity from the resulting heightening of contrasts, in episodes showcasing taboo language, for example (see below). Spanish on the other hand keeps closer to the source dialogues, and to the English subtitles, in the most literal representation in the dataset. It seems that English subtitles may have been used as pivot, albeit to a greater or lesser extent across the set. This has significant implications. It makes linguistic uniformization more likely, as an inbuilt factor of mode idiosyncrasy. The practice may have historical roots, in past censorship for example, e.g. for Spanish or Italian, or different cinematic traditions. Or it could perhaps be traced to linguistic features and orientations, e.g. varying tolerance across languages to the implicitness and elliptical expression in evidence in the French data, for example.

What is more critical for research, however, is the impact of textual literalness vs. streamlining/stylization on audiences' responses, in relation to questions of cultural a-synchrony and the 'shining through' of linguistic and cultural otherness. These questions are taken up in Section 5.

A second striking feature of the data is the limited volume of 'critical points', or points of conspicuous decision making in target texts signalling translation problems (Munday 2018:180), and its implications. Subtitling has no scope to be fully literal: it does not have the screen space and time, linguistic and cultural mismappings across languages rule it out. Cultural references, taboo language, language varieties, humour are all standard challenges for representation, for example, and are documented extensively in research and practice guides, so perhaps warping our perceptions of their frequency in practice. They are in evidence in the MBS dataset, but the text is otherwise straightforward to translate. Subtitles are on the whole calqued quite closely on the English supposed pivot, itself a streamlined but close representation of make-belief stylized dialogues. This has two key consequences: resulting uniformization promotes hybridization, and makes it an integral feature of the subtitling mode; difference itself is more conspicuous, and its impact is amplified. The more sameness there is in text, the more difference stands out and matters expressively, however slight. This applies to punctuation, for example. It extends to linguistic features like FPMs/discourse markers, terms or pronouns of address and other elements signposted by comparative analysis in the next section, and discussed in their integrated interplay. The impact of difference is fully dependent on their close interaction.

The difference that small variations can make is illustrated below with a brief account of representations in Extract 1 of the 'fuck' expletive documented in the data in the initial phase of the work. The example also encapsulates two other major features of subtitling: vertical internal indexing and verticality of text processing. Extract 1 is the first in which the expletive is used - twice by Lee, as 'fuck' and 'fucking', as shown below in Table 1. In contrast with the other languages and their reliance on similarly offensive terms, French opts for what appears out of context to be a milder representation (je m'en tape pas mal [90] [I don't give a toss]), and just once. In context, however, the seemingly milder representation takes on comparable pragmatic force, i.e. marks the amplitude of Lee's venting of his so far contained exasperation at the point of utterance. It becomes internally indexed as comparatively offensive by the same token, and is set in this value for subsequent uses in the scene or film. The three factors identified above, line segmentation, line 
distribution and punctuation are instrumental in this. There are others, illustrated in a small subset of Lee's lines in Table 1 below.

In these lines, the linguistic bareness of extreme stylization heightens contrast: between bland minimal expression reflecting Lee's uncommunicative state of being at the time, and the limited but perceptible markedness of the mild(er) expletive used, emphasized by line segmentation and distribution and punctuation. Pragmatic impact at this point is also vertically dependent on the noticeable contrast with Lee's verbal expression in an earlier scene, the opening sequence for the film. His talk at that point was extended, multiclausal, lexically diverse, free and easy interactive banter with his nephew and his brother. His utterances in the janitor scene are strikingly different: they are all confined to one line in the French subtitles; they are punctuated with full stops that preclude any form of interactional engagement, unlike the question marks and ellipsis frequent in the opening scene; and they feature no interactive FPMs, downtoners, pronouns of interpersonal engagement or second parts in adjacency pairs, and no verb aspect, in contrast with corresponding subtitles in English (see Guillot, 2019 for a full account).

Context - Mrs Olsen's bathroom. Lee has been called in to fix a leak from the shower. He thinks the bath needs re-caulking (the referrent for 'it' at [91] below). He suggests running the shower to check [93]. Mrs Olsen then pretends she is being asked to take a shower in front of him and responds aggressively and provocatively. She has been incensed by Lee's uncommunicative behaviour, further evidenced in his response here $(98,99)$.

The lines below are Lee's responses to Mrs Olsen at this point (with just one 'Okay' second pair part from her for English, but not French), out of their dialogic context to highlight their formal and linguistic blandness, and the markedness and pragmatic impact in this context of the option chosen for the expletive in French.

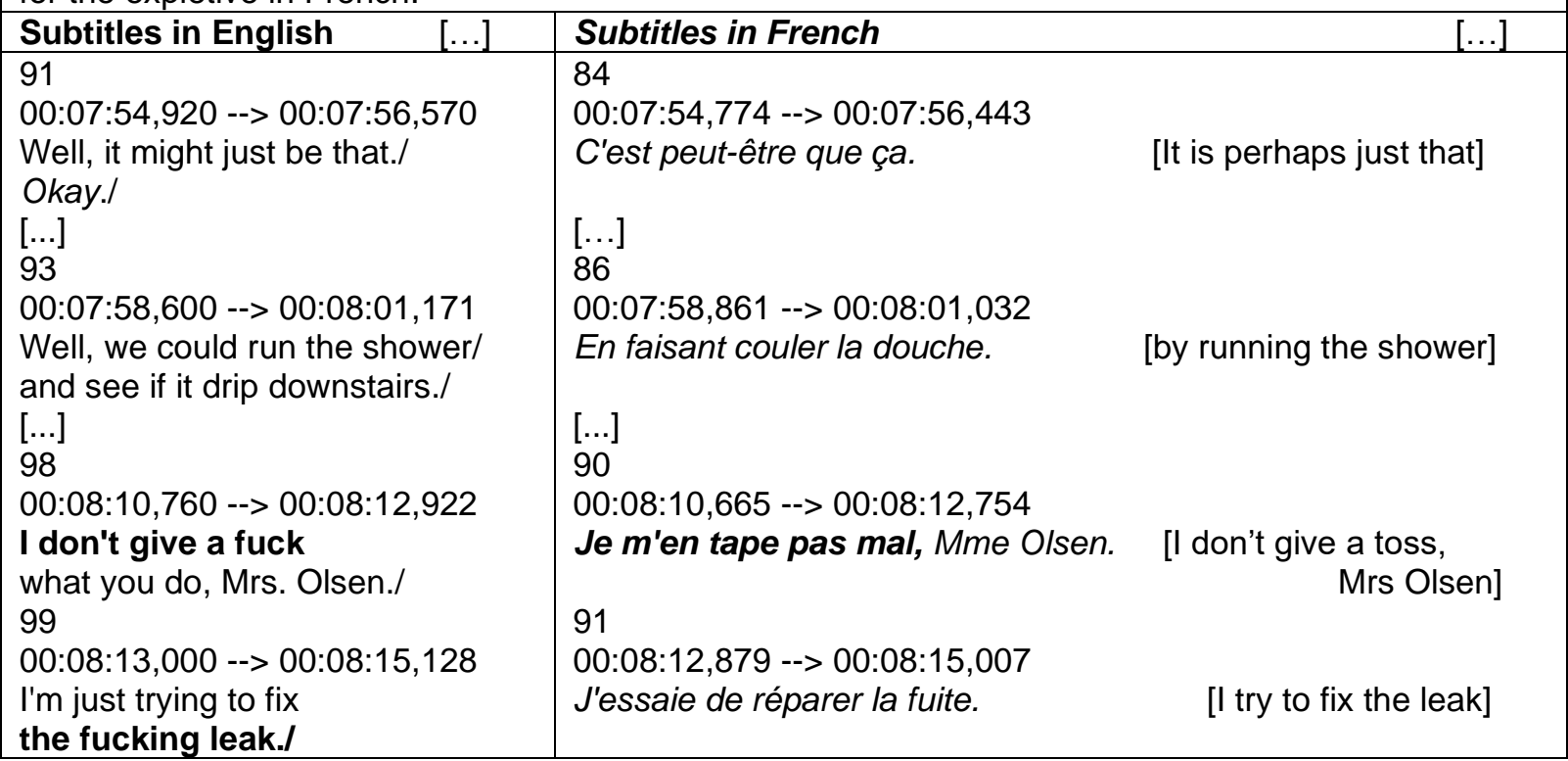

Table 1 Lee's use of expletives in Extract 1 - subset of illustrative lines ${ }^{1}$

\footnotetext{
${ }^{1}$ Time codes and subtitle set numbers are shown in this table in their standard presentation, as an indication of differences in the overall number and distribution of subtitles, here for French and English. Time codes are omitted from subsequent samples of text to reduce cluttering.
} 


\section{Data analyses}

This section turns to functional pragmatic markers, identified as of interest in the first part of the work, and the object of some attention for single language pairs in AVT, though mostly for dubbing. Other types of features of potential relevance for this kind of study are briefly itemized at the end of the discussion.

Functional pragmatic markers (FPMs) encompass pragmatic markers (PMs), discourse markers (DMs) and modal particles (MPs). There is still limited agreement on terminology and the classification of these entities, despite the large body of work on their properties (Fedriani and Sansó; 2017:1, Fraser 2015: 48, Furkó, 2020:1-2 inter alia). Fedriani and Sansó define them as follows, as baseline terminological conventions to establish common ground for contributions to their 2017 edited volume on the topic, and avoid unhelpful definitional discussion impasses: PMs are identified as markers of social and interpersonal cohesion (hearer-speaker relationship, social identity, type of social act performed - e.g. please, danke, if could interrupt, etc.); DMs as strategies ensuring textual cohesion (discourse planning, discourse managing; e.g. utterance initial uses of but, anyway etc.); MPs as signals of speakers' evaluation of the information status of their utterance (e.g. ja, doch for German) (Fedriani and Sansó 2017, 2). There is broad consensus on main attributes and shared characteristics: they are polysemic, multifunctional and flexible in use, there is frequent overlap in their meanings and functions beyond core values, their position can affect both. But boundaries between them remain fuzzy and subject to much debate in research, within languages and contrastively, from Schiffrin's 1987 milestone study to Aijmer's 2013 staple contributions to contrastive work up to her most recent (2020), among many others.

Subtitling itself falls between stools. Subtitles are fiction several times over, at the research interface of speech and writing and fictional representation across genre and media. There is more variability in FPM studies across these different domains than there is space to account for here (see Furkó's 2020 enquiry across genres and critical perspectives, for example). Subtitling is at any rate a special case in its capacity to index pragmatic and textual meaning, as a crossover mode also idiosyncratically modulated by space, time and readability factors. That is a primary focus for the discussion. Layout and spatial distribution of text across frames are significant in this respect. They blur boundaries and functions further for FPMs, and affect positioning, identified in Beeching and Detges' (2014) contrastive work as having an impact on their expressing textual, subjective and intersubjective meaning in clause peripheries. These are unusual factors. They justify a bottom-up form-tofunction approach, common for FPMs in view of the all-round flexibility that is one of their trademarks (Aijmer, 2020; Furkó, 2020), with broad properties as a framework in the first instance.

For the purposes of this study, FPMs are thus considered under a single FPM label, based on shared characteristics: they are not obligatory and removing them does not affect propositional meaning; they can have procedural functions, i.e. constrain interpretation by signposting how propositions/utterances are to be processed, in a "co-built coherent representation of discourse"; several can normally fulfill the same function, and conversely, each can fulfil several functions, in variable positions, usually left or right periphery (Fedriani and Sansó; 2017:3-4).

FPMs are explored below in Lee's near-monologic police interview from Extract 2, where they punctuate his recounting of the events leading to the fire tragedy temporally and causally. 


\subsection{Functional pragmatic markers - overview in AVT and the MBS data}

Cross-linguistic studies of FPMs concur on basic points: there is limited functional correspondence across languages; overlaps derived from FPMs' polysemy and polyfunctionality complicate matters (Aijmer 2007; Crible and Pascual, 2019; Cuenca, 2008; and others). That is a main issue for translation. It is compounded in AVT by further factors in constructing the fictional reality of written-to-be-spoken source dialogues interlingually. These include synchrony for dubbing and, additionally for subtitling, the diasemic shift from speech to writing and need for easy readability.

In AVT, FPMs/DMs have been associated with questions of naturalness and/or orality. Loss is a frequent leitmotiv. The main strategies observed are reduction by omission, literal translation and functional equivalence. They are shown to privilege semantic meaning over interpersonal meaning. This tendency is deemed to affect the balance between these types of meaning, and sometimes reduce coherence (see e.g. Bruti and Zanotti, 2016 for subtitling, and for dubbing Chaume, 2004; Cuenca, 2008; Freddi and Malagori, 2014; Romero Fresco 2009; Valdeón, 2008).

The MBS data in this study provide other and overall more positive insights, in what they demonstrate of the distinctive expressive potential of subtitles. While there are omissions in the MBS subtitle data, many are meaningful in their own right. And where there are FPMs, their occurrence is marked and gives subtitle text added value. There are also a few additions. In a context where reduction prevails, these additions become particularly noteworthy. There are otherwise small but meaningful changes in the value of FPMs. Significantly, they are a function of syntactic segmentation and distribution across frames, and of the pragmatic impact of punctuation. Together, these factors affect positioning and focalization, and the import of FPMs. This is a new and important point as well, in itself and for further research. In the dataset, the range of FPMs across both source and interlingual representations is limited. There is in this sense limited expressive specificity to be observed across languages. Core use of a subset is critically relevant, however, not only as a feature of the mode, but also for its capacity to trigger (over)-frequency as a meta-indicator of otherness. There are semantic and functional overlaps in the FPMs present in the dataset. They can blur differences. Yet they are also the locus of potential differentiation, and have implications as regards distinctive use and the 'shining through' effect.

Together, the features just discussed make a tangible difference. The most striking aspect here again is the impact of form, including for the categorization of the items to be considered as functional markers in the encoding of text. It is illustrated below for Extract 2, in 4.2; a sample section is discussed in detail in 4.3.

Five tables are used in the discussion: Table 2 below is a transcription of the Extract 2 source dialogues (SD). Table 3 shows FPMS in Extract 2 overall across languages, by frequency of occurrence. Table 4 shows a diagrammatic distribution of FPMs in Extract 2's opening sequence (SD lines 1-13). Table 5 is a sample section considered in detail in 4.3 (7-13); Table 6 is a complementary example, from the end of Lee's monologue/Extract 2 (33-37). 


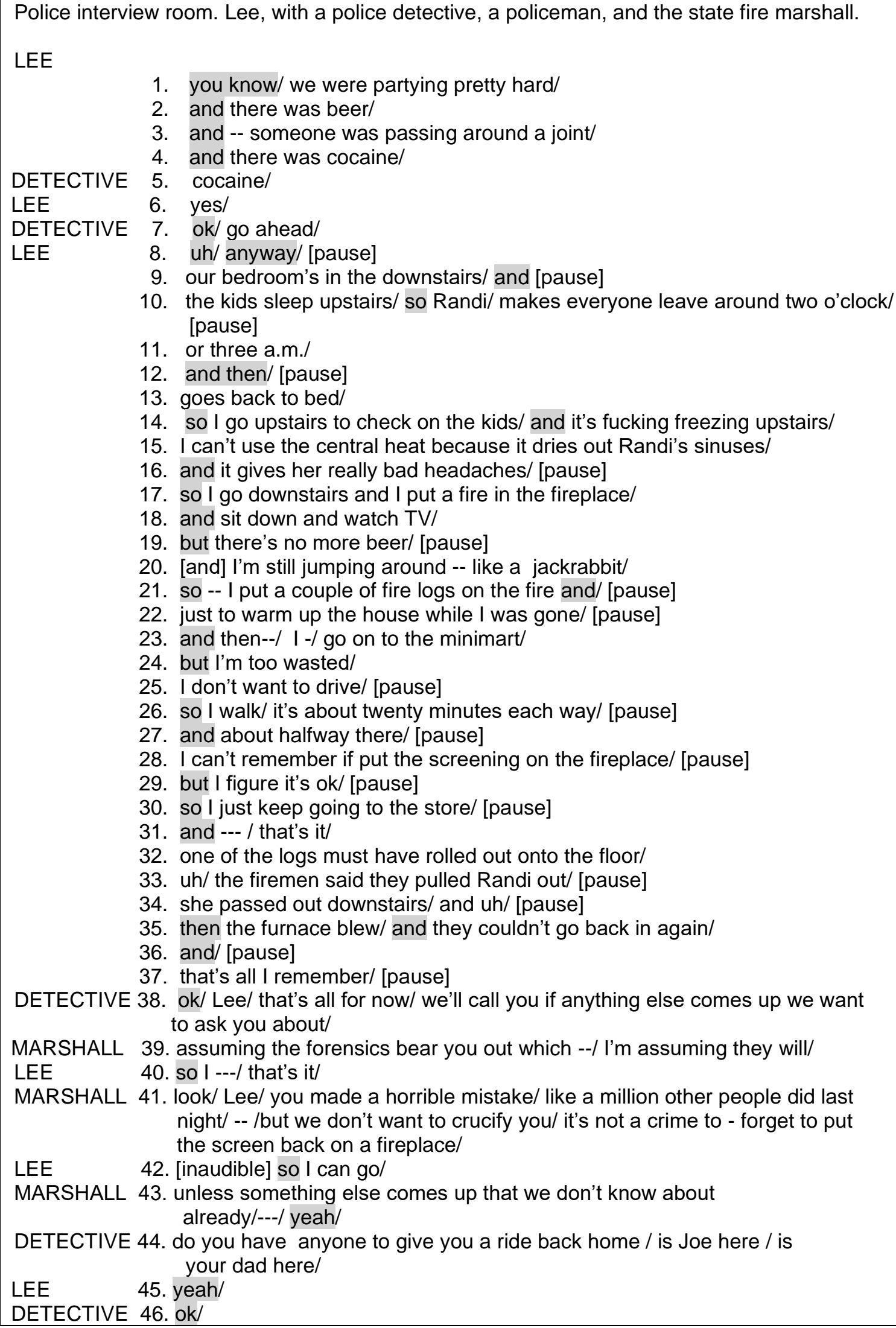

DETECTIVE 38. ok/ Lee/ that's all for now/ we'll call you if anything else comes up we want to ask you about/

MARSHALL 39. assuming the forensics bear you out which --/ I'm assuming they will/ LEE 40. so I ---/ that's it/

MARSHALL 41. look/ Lee/ you made a horrible mistake/ like a million other people did last night/ -- /but we don't want to crucify you/ it's not a crime to - forget to put the screen back on a fireplace/

LEE 42. [inaudible] so I can go/

MARSHALL 43. unless something else comes up that we don't know about already/---/ yeah/

DETECTIVE 44. do you have anyone to give you a ride back home / is Joe here / is LEE 45. yeah/ your dad here/

DETECTIVE 46. ok/ 
Table 2 Manchester by the Sea - Extract 2 source dialogues transcription lines 1-38; / denote tonal groups; --- denote pauses.

\begin{tabular}{|c|c|c|c|c|c|c|c|c|c|c|c|}
\hline \multirow{2}{*}{\multicolumn{2}{|c|}{ SD transcription }} & \multicolumn{10}{|l|}{ Subtitles } \\
\hline & & \multicolumn{2}{|l|}{ English } & \multicolumn{2}{|l|}{ French } & \multicolumn{2}{|l|}{ German } & \multicolumn{2}{|l|}{ Italian } & \multicolumn{2}{|l|}{ Spanish } \\
\hline and & 16 & A/and $5+11$ & 16 & Et/et $1+9$ & 10 & U/und $4+7$ & 11 & E/e 2+6 & 8 & $\mathrm{Y} / \mathrm{y} 5+9$ & 14 \\
\hline so & 8 & S/so $6+1$ & 7 & Alors $1+2$ & 3 & Also & 3 & $\mathrm{Ma} / \mathrm{ma} 2+2$ & 4 & A/así & 5 \\
\hline but & 4 & Uh & 5 & $\mathrm{M} / \mathrm{mais} 1+2$ & 3 & A/aber $1+2$ & 3 & Q/quindi2+1 & 3 & que $4+1$ & 4 \\
\hline uh & 3 & but & 3 & $\mathrm{P} /$ puis $1+1$ & 2 & Okay & 2 & Bene & $3^{*}$ & pero & 2 \\
\hline & 3 & Okay & 2 & Bien & 1 & $\mathrm{D} /$ darum & 2 & Poi & 3 & Vale & 1 \\
\hline you know & 1 & Anyway & 1 & voilà & 1 & & 1 & Comunque & 1 & luego & 1 \\
\hline $\begin{array}{l}\text { anyway } \\
\text { then }\end{array}$ & $\begin{array}{l}1 \\
1\end{array}$ & Well & 1 & & & $\begin{array}{l}\text { Dann } \\
\text { Nur } \\
\text { (damit) }\end{array}$ & 1 & & & entonces & \\
\hline and then & 2 & $\mathrm{~A} /$ and then & 3 & Et donc & 1 & $\begin{array}{l}\text { Und dann } \\
\mathrm{Na} \mathrm{ja}\end{array}$ & $\begin{array}{l}3 \\
1\end{array}$ & & & Y luego & 1 \\
\hline 9 different & 36 & 8 different & 38 & 7 different & 21 & 8 different & 27 & 6 different & 22 & 7 different & 28 \\
\hline
\end{tabular}

Table 3 FPMs in Extract 2, by frequency of occurrence. FPMs are shown with and without the capitalization observed in the subtitles as this is relevant for the discussion

\subsection{Overview of FPMs in Extract 2}

Lee's monologic SD narrative in Extract 2 relies on a subset of just three main pragmatic functional items, in utterance-initial or utterance internal position: 'and', 'so' and 'but', as markers of chronology and causal relationships (16, 8 and 4 occurrences respectively) (see Table 3).

They provide the structural framework and textual cohesion for a mostly paratactic account, conveyed in short spurts of factual information in independent or coordinated simple sentences, with few dependent clauses (just 2). There are also two occurrences of the two-word item 'and then'. In the subtitles, each introduces one of the two main triggers in the chain of events leading to the tragedy, for which Lee feels responsible, and frames them (Randi going back to bed; Lee leaving the house for the minimart). In the SD, they bring prior sequences to a close, and provide a platform for the next. There is otherwise one occurrence of 'you know' that sets in motion Lee's account of the events leading up to the tragedy and its aftermath (represented as 'Well' in the subtitles), and one of 'uh, anyway' marking the return to his narrative after a short clarification request from the detective present. Both of these occurrences also have clear functions, as interactive markers of social and interpersonal cohesion.

In the SD, so/and/but produce a recurring pattern in Lee's step-by-step retelling of facts in their chronological sequence and consequences, and provide a framework for them that becomes almost redundant with the regularity they produce. They render explicit relationships that could be inferred from propositional content in the series of simple sentences that they give overt cohesion to. Repetition heightens the drama of the build-up of events, however, and the pain of its recollection for Lee. Diagetically, their use has structural functions, and emotionally underpins Lee's stepby-step inward and verbal reconstruction. Extra-diegetically, it draws audiences into the drama and the intense emotional involvement of its blow-by-blow FPMpunctuated reconstructive account. This is intensified in the SD by pauses of increasing length as Lee's statements take him back further introspectively, up to the 
point of the actual tragedy, though that is never mentioned directly, only in its (reported) aftermath. Together, the repetitive build-up of FPMs and prominent pausing are an index of Lee's guilt-ridden distraught state, also in evidence in his body behaviour and voice quality.

In the subtitles, the drama and pathos are produced by FPM omission and resulting linguistic starkness, syntactic segmentation cum punctuation, and the segmentation and distribution of lines across frames. They combine in different ways across languages, and have different structural and narrative bearing. This is shown complementarily in Tables 3 and 4 (full range and frequency of occurrence of FPMs across the Extract 2 dataset [Table 3], and distribution of FPMs in diagram form for the [sample] opening sequence of Extract 2 [Table 4]. 


\begin{tabular}{|c|c|c|c|c|c|c|}
\hline Extract 2 Source dialogues [1-13] & FPMsSD (transcription) & English & French & German & Italian & Spanish \\
\hline LEE to DETECTIVE - party, beer, cocaine & you know /---/ & Well, ---. & $\varnothing---$. & $\begin{array}{l}\varnothing---, \\
\text { und ---. }\end{array}$ & $\varnothing---$. & $\varnothing--$. \\
\hline \multirow{2}{*}{$\begin{array}{l}1 \text { you know/ we were partying } \\
\text { pretty hard/ } \\
2 \text { and there was beer/ } \\
3 \text { and .. someone was passing } \\
\text { around a joint/ }\end{array}$} & and ---/ & And ---. & $\varnothing---$ & & $\varnothing---$ & $\varnothing---$ \\
\hline & and [pause] ---/ & And ---. & $\begin{array}{l}\varnothing-- \\
\text { et ---. }\end{array}$ & $\begin{array}{l}\text { Und ---, } \\
\text { und ---. }\end{array}$ & $\varnothing--$. & y ---. \\
\hline \multirow{4}{*}{$\begin{array}{lll}4 & \text { and there was cocaine/ } \\
5 & \text { 1ST DETECTIVE } & \text { cocaine/ } \\
6 & \text { LEE } & \text { yes/ } \\
7 & 1 S T \text { DETECTIVE } & \text { ok/go ahead/ }\end{array}$} & and --- & and ---. & & & e ---. & \\
\hline & $---?$ & $---?$ & $---?$ & $---?$ & $-\cdots ?$ & $---?$ \\
\hline & yes & Yes. & $\varnothing$ & - Ja. & - Si. & Si. \\
\hline & ok/ & Okay,---. [vb you] & Bien, ---. [vb T]. & Okay, [adv]. & {$[\mathrm{vb} T]$} & Vale,---. [vb T] \\
\hline \multirow{7}{*}{$\begin{array}{l}\text { Context, } \text { Randi makes all leave, goes back to bed } \\
8 \text { uh/ anyway/ ... } \\
9 \text { our bedroom's in the downstairs/ } \\
\text { and/... } \\
10 \text { the kids sleep upstairs/so Randi/.. } \\
\text { makes everyone leave around two } \\
\text { o'clock/ ... } \\
11 \text { or three AM/ } \\
12 \text { and then / ..... } \\
13 \text { goes back to bed/ }\end{array}$} & Uh/ anyway.../ & Uh, anyway, ...., & Et donc... & $\mathrm{Na} \mathrm{ja...}$ & $\begin{array}{l}\text { Comunque... ---, } \\
\text { e... }\end{array}$ & $\varnothing$ \\
\hline & ---/ and [pause] / & --- & --- & $\begin{array}{l}\text {----, } \\
\text { und --- . }\end{array}$ & --- & --- \\
\hline & ---/ so --- [pause] / & --- & $\begin{array}{l}\text { et ---- } \\
\text { alors --- }\end{array}$ & $\varnothing--. .$. & $\begin{array}{l}\text { e --- } \\
----, \text { quindi --- }\end{array}$ & $\begin{array}{l}\text { y ---, } \\
\text { asì que --- }\end{array}$ \\
\hline & ---/ [pause] / & $\begin{array}{l}\text { so --- } \\
---.\end{array}$ & --- & & --- & --- \\
\hline & $---/$ &.--- & $---\ldots$ & &.--- & --- \\
\hline & and then / [pause] / & And then... & puis... & Und dann... & Poi... & Y luego \\
\hline &.--- & --- &.--- & --- . &.--- & --- . \\
\hline
\end{tabular}

Table 4 Diagrammatic distribution of FPMs in Extract 2 - sample from the opening sequence; / denote breaks between tonal groups in the SD;

... denote pausing in the SD and ellipsis in the subtitles; --- correspond to simple sentences in the subtitle text spelled out in full in Table 2 
There are 21, 22, 27 and 28 occurrences of FPMs in the Extract 2 data for French, Italian, German and Spanish respectively, as against 36 and 38 each for SDs and their subtitles in English, and a range of 9 and 8 different types respectively (Table 3). The range for the other languages is no more diverse overall. It is in line with observations for dubbing, where it is likewise restricted to a cluster, with also lower frequency than in spontaneous speech (Chaume, 2004 for Spanish, Herbst, 1997 for German, Pavesi, 2008 for Italian). Pavesi thus notes that the so called 'weak connectors' (i.e. creating no syntactic dependencies) are limited in number in her Pavia corpus of translated films - just over a third of their occurrences in spontaneous speech, with only $e$ [et] and $m a$ [but] anywhere near their frequencies in Italian conversations (Pavesi, 2008:87). Clustering on a small core set may also be symptomatic of subtitling idiosyncrasy, with implications of their own for this mode, as shown in the example discussed further below.

The range is limited and it also appears specialised in functions set internally, in line with a process observed for greeting terms, for example, in MBS and other data: just two greeting terms are used for French in the full MBS data, bonjour as broad default address, salut for children, and leave taking (once), vs.against 'Hiya', 'Hello', 'Hi', 'good bye' for English, in a subset that is likewise pragmatically pared down by comparison with authentic speech (Guillot, 2019; see 2016b for other films ${ }^{2}$ ). For all languages, broadly multifunctional 'and' and equivalent et [French], und [German], $e$ [Italian], and $y$ [Spanish] are the most recurrent FPMs. French relies on two main other options for causal and temporal linking: alors (more causal) and puis (more temporal and end of enumeration marker). Their functions are derived from what sets them apart rather than what they share, i.e. from differentiation rather than overlap, and are used with strategic structural impact, for French and for the other languages: from more causal to more temporal for Spanish with asi que, (more formal) entonces and luego; for the three options for German, also, darum and dann, with darum reflecting the German language's capacity to generate combined connector particles. For Italian quindi is causal and poi temporal with no overlap and more marked differentiation. They embody the settings given as core values to corresponding options in the other languages.

Positioning and pragmatic value are other aspects of difference. In English, the strong adversative function of 'but' keeps it away from face-threatening utterance initial position (see e.g. Haselow, 2019), i.e. without prior mitigation. By contrast equivalents for French (mais) and Italian ( $m a$ ) are both interactive and not necessarily adversative, and so common at the onset of utterance as turn-taking tools (Guillot, 2011, Pavesi 2008). Extract 2 is not interactive as it is mostly monologic in nature. But it is interesting to note that while there are occurrences of Ma and Mais (and indeed Aber) in Extract 2 in sentence initial position, there are none of 'but' in the English subtitles, a feature worth exploring further, in itself and for implications as regards intercultural mediation.

How these expressive differences and other placement options may play out is taken up below. Analyses apply to a section of Extract 2 from near the beginning of the police interview (SD lines 8-13, Table 5) and related examples from later (3337, Table 6), and illustrate principles that extend beyond FPMs.

\footnotetext{
2 Discussion of greetings and other communicative practices in Hidden (Caché) (Haneke, 2005) (French), Paris (Klapisch, 2008) (French), Volver (Aldomovar, 2006) (Spanish).
} 


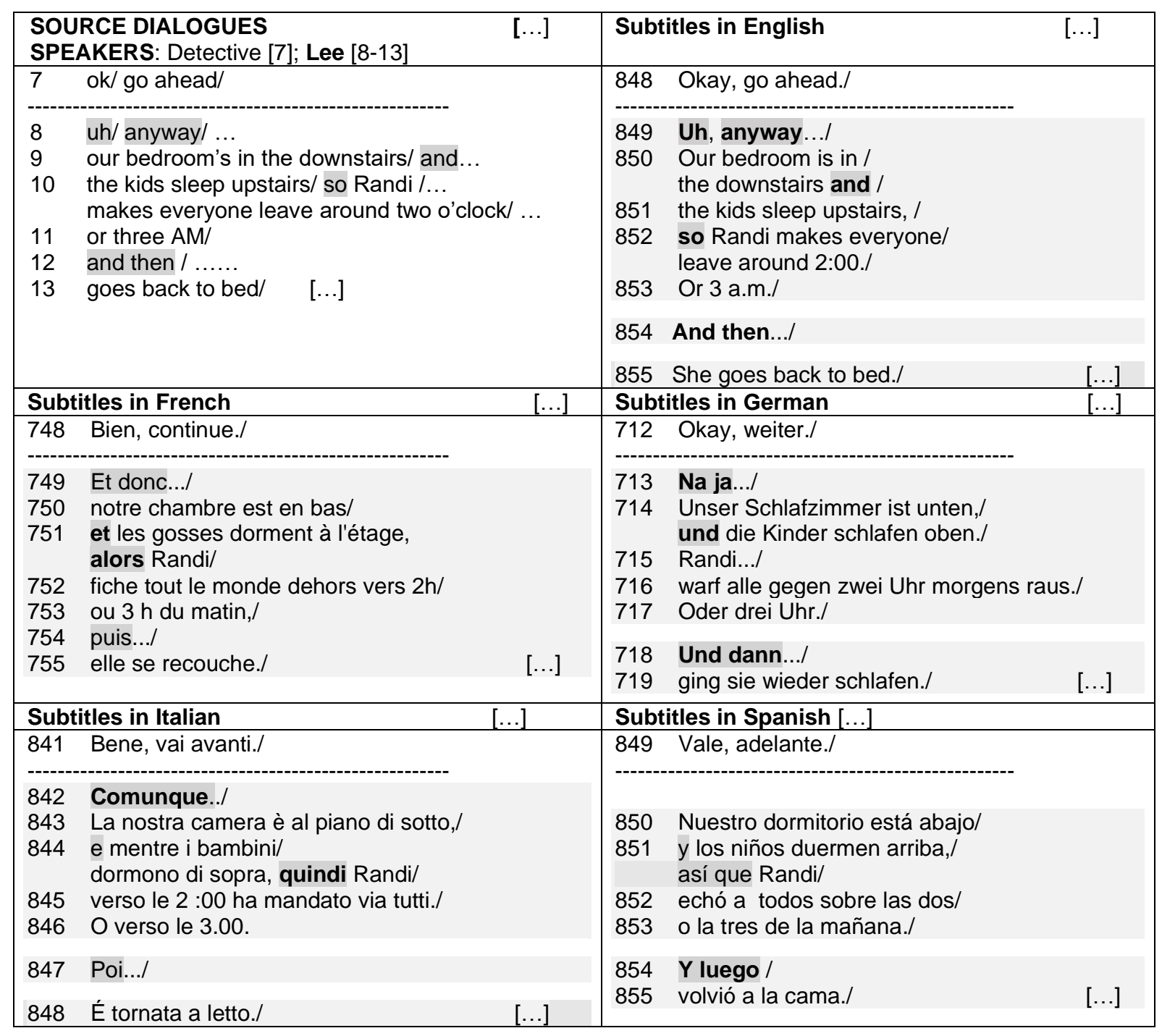

Table 5 Example from Extract 2 - Police Interview opening sequence; / denote tonal groups in the SD and subtitle boundaries in the subtitles; ... denote pauses in the SD and ellipsis in the subtitles.

\subsection{MBS FPMs in context - example from Extract 2}

The most striking feature in the Table 5 example is how different interpretative frames are projected: the English, German, Italian and Spanish versions are similar (albeit with some variations across them as well) but differ noticeably from the French rendering. The difference stems from how FPMs modulate representation, in interplay with other features. This is particularly striking for the first 'and then' from the SD extract, at line 12 in the SD transcription, and the subsequent (two) examples for which this first occurrence is a structural template/platform. Punctuation and syntactic distribution within subtitle sets and across frames are instrumental in generating variants.

There are four causally-linked contextualisating facts in Lee's account in the early part of Extract 2 shown in the example, with temporal anchoring for the last:

- fact A) his and Randi's bedroom is downstairs;

- fact B) the children sleep upstairs;

- fact C) Randi makes everyone leave [from a party Lee had with friends] at around 2.00, or 3 a.m.; 
- fact D) she goes back to bed.

In French, SD 'and then' is represented as puis [754] [+temporal/end of enumeration]. It is part of a joined-up sequence: with [coordinating] et and [+ causal] alors [751], encodes the text as a single utterance over 7 frames, starting with $E t$ donc [749] [And so], in a speech-like paratactic build-up of the four facts.

In the sequence, et occurs between fact $A$ ) and fact $B$ ) at the onset of fact $B$ ) at [751], alors between fact $B$ ) and the first part of fact $C$ ) in the SAME [751] subtitle set. The causal connection between facts $A$ ), B) and $C$ ) is thus visually reinforced but there is a conspicuous break after 'Randi', the agent of an action only disclosed in the next frame/subtitle [752]). This creates a de facto pause, and a reflective hiatus in Lee's reconstruction. The puis occurs between facts $C$ ) and D) on its own, with a pause denoted by ellipsis [754] and with the same kind of pathos-heavy holding function prior to disclosure of fact D) in the next subtitle [755].

There is no such single sequence in the other languages. In all other subtitled renderings the narrative content presented as fact $D$ (she goes back to bed) is set apart, by capitalized sentence-initial FPMs: And then... for English [854], Und dann... for German [718], Poi... for Italian [847] and Y luego for Spanish [854]. All show on their own in a single line, all but Spanish with ellipsis (see Table 5). The pausing focalises reflective introspection, or reluctance to recall, or both. It intensifies the dramatic significance of fact D), as one of the triggers in the set of events leading to the tragedy. Its setting apart from the preceding sequence in one or more subsequences compounds the impact. French has a 7-frame single utterance. German and Spanish have $5+2$ over the 7 frames. Their last proposition is part of the same syntactic unit as Und dann... and luego, albeit in different subtitles (ging si wieder schlafen. [719]; volvió a la cama [855]). English and Italian have a 5+1+1 sequence: capitalisation at the beginning of the last proposition in each case makes it a separate syntactic unit, and co-engages readers/viewers further with Lee in the pathos of the step-by-step syntactically interrupted reconstruction (She goes back to bed. [855]; É tornatta a letto. [848]).

The FPMs at this point take an additional function, as extradiegetic markers in the hierarchization and dramatic foregrounding of recounted events. They are visually enhanced as single elements in their host subtitle, and reinforced in their function by the sequential break before the next subtitle on the next frame. In some cases, typography generates additional syntactic fragmentation. The expressive potential here again is not language-specific but medium- and mode-specific.

There are other points to note in this short extract, all feeding into the overall expressive complexity of the subtitling text, and evidence of a powerful interplay of linguistic and form features in generating nuances of diegetic and extradiegetic pragmatic meaning, with remarkable economy.

i) Omissions - of the 'and' connector at the 'And then' point in Italian and French, in different utterance configurations: Poi... and puis..., as against And then..., Und dann... and $Y$ luego. Like other such cases in the extract, these omissions are expressive. There are more omissions as the scene proceeds and as Lee's recollection gets more painful. They are a covert index of Lee's distress, and call on audiences to engage further and further in co-constructing the text and events with him on the basis of fewer clues, though with support of patterns established earlier with overt FPMs (e.g. and/so/but). The less overt coherence, decried as loss in the literature (see 4.1), has here an expressive function, and a role to play 
in engaging audiences in narrative co-construction. FPM omissions can produce other types of effect - heightening distance and intractability in verbal exchanges, for instance, as evidenced repeatedly in the Janitor scene in Extract 1, with a typical omission of the 'Well' present in the subtitles for English in Table 1.

ii) Position, with impact on focalization, within or at the periphery of subtitle lines, and within or across subtitle sets, in relation to subtitle segmentation and distribution. The siting of connectors between facts $A$ ) and $B$ ) is an example: 'and' for English occurs at the end of a line [850], with a marked suspensive break before the next frame and ensuing occurrence of line-initial causal 'so' [851]. By contrast et, e and y for French, Italian and Spanish occur at the onset of the first of two lines, in sets also featuring line-initial causal alors [French 751], así que [Spanish 851] or line-internal quindi [ltalian 759], in closer interconnectedness. There is no causal FPM in German, for which und shows in a set encompassing both facts $A$ ) and B). These different configurations affect the functional prominence of FPMs and their pragmatic impact, on the way events are projected and the relationship between them.

iii) Punctuation, with the example of the comma in Lee's 'Uh, anyway...' [849] after the detective's query about cocaine at the party (presumably illegal). Corresponding elements in French (Et donc ... [749], German (Na ja ... [713], and Italian (Comunque ... [758] are all without a comma, and project wholly cataphorically into Lee's return to his account. They are also markers of social and impersonal cohesion, but as a single FPM unit, or none in case of omission [Spanish]. Kept apart by the comma, 'Uh' links cataphorically back to the interruption, as a slight incredulous double-take on the invitation to proceed regardless of the cocaine offense. There is then an anaphoric shift of focus back to the retelling with 'anyway...', with a slight effort encoded by the ellipsis, as in the other languages. Further down, there is splitting apart by a full stop and across two subtitle sets of '[...] around 2:00.' [851] and 'Or 3 a.m.' [852]. The split is there in German and Italian, but not in unpunctuated French and Spanish. The contrast between sequential fragmentation and continuity here again illustrates the pragmatic impact of punctuation on the interpretation of frames.

There is no FPM addition in the part of Extract 2 considered above, but the pragmatic impact of addition on the projection of interpretative frames can be demonstrated with an example from the end of Lee's account. It involves the last of the three occurrences of 'and then' that in the subtitles structurally demarcate Lee's retelling in three sequences of temporally and causally related events, and features a reference to the firemen's post-tragedy analysis. The second instance largely echoes the first just discussed in terms of representation, albeit with streamlining to just $E t$ for French and omission for Spanish. In the passage featuring the third occurrence of 'And then' in Table 6, however, there is a small but significant addition, of a simple connector. It is one of very few FPM-related additions in Extract 2, and has conspicuous bearing on the projection of the facts accounted for: "the furnace blew and they [the firemen] could not go back in again" (i.e. for the girls, after the rescue of their mother from the fire) [SD 35] (Table 6 below). 


\begin{tabular}{|c|c|c|c|c|c|}
\hline \multicolumn{6}{|c|}{ Source dialogue transcription } \\
\hline \multicolumn{6}{|c|}{$\begin{array}{ll}{[\ldots]} & \\
33 & \text { uh/ the firemen said they pulled Randi out/ ... } \\
34 & \text { she passed out downstairs/ and uh/ ...... } \\
35 & \text { then the furnace blew/ and they couldn't go back in again/ } \\
36 & \text { and/ .... } \\
37 & \text { that's all I remember/ } \\
{[\ldots]} & \\
\end{array}$} \\
\hline \multicolumn{2}{|c|}{ Subtitles in English } & Suk & btitles in French & $\mathrm{Su}$ & otitles in German \\
\hline $\begin{array}{l}{[\ldots]} \\
874\end{array}$ & $\begin{array}{l}\text { The firemen said/ } \\
\text { they pulled Randi out./ }\end{array}$ & $\begin{array}{l}\ldots] \\
775\end{array}$ & $\begin{array}{l}\text { Les pompiers ont dit qu'ils } \\
\text { avaient sorti Randi./ }\end{array}$ & $7 \ldots]$ & $\begin{array}{l}\text { Die Feuerwehr sagte,/ } \\
\text { dass sie Randi rausholen konnten./ }\end{array}$ \\
\hline 875 & $\begin{array}{l}\text { She had passed out/ } \\
\text { downstairs./ }\end{array}$ & 776 & $\begin{array}{l}\text { Elle était en bas, sans } \\
\text { connaissance./ }\end{array}$ & 740 & $\begin{array}{l}\text { Sie war unten bewusstlos } \\
\text { geworden./ }\end{array}$ \\
\hline 876 & And, uh.../ & & & 74 & Und.../ \\
\hline $\begin{array}{l}877 \\
878\end{array}$ & $\begin{array}{l}\text { And then the furnace blew,/ } \\
\text { and they couldn't go back } \\
\text { in again./ }\end{array}$ & 777 & $\begin{array}{l}\text { Puis la chaudière a explosé,/ } \\
\text { ils ont pas pu retourner à } \\
\text { l'intérieur./ }\end{array}$ & 742 & $\begin{array}{l}\text { Und dann ist der Kamin geborsten,/ } \\
\text { und sie konnten nicht wieder rein./ }\end{array}$ \\
\hline 879 & And...l & & & 743 & Und.../ \\
\hline 880 & That's all I remember./ & 778 & Je me rappelle rien d'autre./ & 74 & $\begin{array}{l}\text { Das ist alles, woran ich mich } \\
\text { erinnere./ }\end{array}$ \\
\hline
\end{tabular}

Table 6 Example from Extract 2 - End of Lee's account of events to the police (/ denote tonal groups in the SD and subtitle boundaries in the subtitles; ... denote pauses in the SD and ellipsis in the subtitles).

As shown for French vs. English and German in Table 6, the addition makes a notable difference in the way facts are projected. For French, they are presented as the last in a string of events retold by Lee first-hand, and temporally introduced as such with Puis [777] in a structural echo of the first. For English and German, they produce a temporary backtracking of (dramatic) recall in the closing sequence. The backtracking is initiated and suspended with And, uh... [876] and Und... [741]. It is then picked up with And... [879] and Und... [743], with in between a return to a citation from the firemen's comments, in reported speech that adds to the facts introduced earlier by 'The firemen said'. All it takes is the simple addition, by comparison with the SD, of 'And' and 'Und' in And then+fact [877] and Und dann+fact [742], at the onset of what capitalization and punctuation with a full stop makes a separate stand-alone syntactic unit, of two subtitles for English [877+878] and one in German [742]. Both are equally dramatic, English for the fragmentation of the recall projected, German for the inevitability that the coordination of the two facts on the same frame highlights.

French may seem bland by comparison, here as in the first example, of its seemingly less dramatic streamlined account of events in single continuous sequences. But blandness and stylization throughout is how French achieves dramatic quality. They are a reflection of Lee's culpable despondency, here in evidence in the overall structure of his account, in combination with other features: simple lexis, simple syntax, preference for single line subtitles that makes two-liners stand out, FPM use confined to a core set, with values indexed on semantic specialisation and thus with greater capacity for differentiation. These features extend to other languages, but to a different and usually lesser extent, or in different ways. 
What matters here again, for structure as for all else, for French and across languages, is not choice at any single point, but relationships between choices in their verticality, in a complex interplay that is integral to what characterizes the pragmatics of subtitling, and subtitling's expressive force, in all its distinctiveness.

\subsection{Other aspects}

FPMs in the mostly monologic Extract 2 sample were essentially textual cohesion markers, semantically and functionally stylized. They are all the more expressive for this very reason, with extra-diegetic narrative functions conspicuously modulated by a set of complex form-related factors. They are predictably more diverse in interactive extracts, and ripe for further exploration on different grounds, as the examples that could only briefly be referred to here suggest. There are other candidates for investigation in the Extract 2 contrastive data. Some of these are the locus of attention in studies of individual language pairs, as translation challenges, but also for their enriching functions. This is the case of pronominal address and T/V shifts (Meister, 2016 and Pavesi, 2012 [English to Swedish and Italian]; Guillot, 2010 [French to English]), and can be seen in the Lee/detective interaction in different T/V instanciations from undifferentiated 'you' across languages (V for German, T elsewhere). Omissions of negative particles in French are likewise relevant: they area marker of orality and register, and flag different facets of narrative or relational work, e.g. je $\varnothing$ me rappelle rien d'autre [I remember nothing else] [778 in Table 6]; they also signpost French's partiality for negative forms, and their expressive potential by comparison with English where they are generally less frequent (here 'That's all I remember' [880] - less incontrovertible in this affirmative form). Indefinite pronouns (e.g. on [French], or man [German]) or recourse to third person impersonal forms, as in the Table 1 example, are other tools for the differentiated projection and modulation of relational work across languages. Instances of shifts to nouns from verbs or adjectives (e.g. 'while I was gone'/pendant mon absence in the extract) signal a capacity to accommodate nominalisations across a broader range of registers, here for French, which has expressive potential (here to produce distance). Different encodings of manner-of-motion across languages can, too, become an expressive asset, even though they are normally identified as critical translation points as a function of asymmetries across satellite- vs. verb-framed languages (e.g. Germanic vs. Romance languages respectively) (Molés-Cases, 2019).

\section{In conclusion - does it all matter?}

What this qualitative contrastive pilot study has demonstrated further, perhaps more than anything else, is the range of formal as well as linguistic options available to induce interlingual representation, out of what are complex interplays, internal forms of indexing, and vertical processes of encoding diegetic and extra-diegetic meaning. Sense-making itself remains, in the end, the privilege of viewers. In this sense AVT, and subtitling specifically, is not about representing, or representation. It is about creating options for representation, ultimately pieced together by receiving publics, about producing signifiers whose signified are reassignable by viewers themselves, with input also from the broader multisemiotic context (see Guillot, 2019).

What then of the question of intercultural mediation, and of the 'shining through' effect hypothesized to keep audiences alert to otherness in relation to their own practices, by dint of instantiations playing to different inferencing frames? Form has elsewhere been shown to play a key role in this, e.g. in the enactment of 
politeness, by covertly counteracting the overt effect of omission, of mitigating features, for example (Guillot, 2010). Here for FPMs, it looks as though there could be other kinds of triggers as well, like frequency, arising from semantic and functional specialization for the core subset of FPMs used across the different languages, in conjunction with the most frequent and multifunctional for all ('and' in sentence initial or sentence internal position and equivalents). That frequency can be a (powerful) meta-indicator of otherness appears to be likely when taking earlier studies on FPMs in dubbing into account. This finding still needs to be ascertained quantitatively with corpus work for subtitling, for FPMs and for other features. There are other pending questions, brought into sharper relief by foregoing observations. The main one pertains to the extent to which stylization, in combination with hybridization, can stimulate a more critical response and intercultural mindfulness by requiring extra cognitive effort for inference. The second, by extension, relates to how literal renderings may compare, in this respect, in relation to questions of linguistic and cultural stereotyping.

Identifying, typologizing, and rationalizing have been critical steps for AVT and have given us a much more robust sense of the range of aspects/features/ phenomena to be observed and taken into account. Resulting generalizations inevitably involve simplification, to an extent that can come in the way of recognizing or acknowledging fully the complexity of what is at play in audiovisual translation. For audiences, this complexity may well occur way below the level of consciousness, but it is the raw material for their responses, what they contend with and build on as viewers, with their own individual sociocultural and viewing profiles. Scope for generalization for the type of work piloted here would be contingent on a research investment that may be out of line with possible return, with extensive multidisciplinary and multilingual collaborative input. All the same, and however much we need a sense of reliable and falsifiable explanatory frameworks and universals, complexity has to be recognized, as the resource in subtitling whereby meaning can be induced, sense be made, and otherness shine through.

\section{Filmography}

Manchester by the Sea. 2016. Dir. Kenneth Lonergan. Screenplay by Kenneth Lonergan. K films Manchester LLC.

\section{References}

Aijmer, Karin, 2007. Translating discourse particles: A case of complex translation. In: Anderman G. and. Rogers M. (Eds), Incorporating Corpora. The Linguist and the Translator. Cleveland/Buffalo/Toronto, Multilingual Matters, pp.31-59

Aijmer, Karin, 2013. Undestanding pragmatic markers: A variational pragmatic approach. Edinburgh: Edinburgh University Press.

Aijmer, Karin, 2020. Contrastive pragmatics and corpora. Contrastive Pragmatics 1,1-30.

Beeching, Kate, Detges, Ulrich (Eds), 2014. Discourse functions at the left and right periphery: Crosslinguistic investigations of language use and language change. Brill,Leiden. 
Bruti, Silvia, 2009. The translation of compliments in subtitles. In: Díaz Cintas, J. (Ed.), New Trends in Audiovisual Translation. Multilingual Matters, Clevedon, pp.226-238.

Bruti, Silvia, Zanotti, Serenella, 2016. Non-professional subtitling in close-up: a study of interjections and discourse markers. In: Antonini, R., and Bucaria, C. (Eds) Non-professional Interpreting and Translation in the Media. Peter Lang, Frankfurt, pp.231-256

Chaume, Frederic, 2004. Discourse markers in audiovisual translation. META 49(4), 833-855.

Cuenca, Mariá-Josep, 2008. Pragmatic markers in contrast: The case of well. Journal of Pragmatics 40(8), 1373-1391.

Crible, Ludivine, Pascual Elena, 2019. Combinations of discourse markers with repairs and repetitions in English, French and Spanish, Journal of Pragmatics, 156, 5467.

Dìaz Cintas, Jorge, Szarkowska Agnieszka (Eds), 2020. Experimental Research in Audiovisual Translation - Cognition, Reception, Production Journal of Specialised translation Special Issue on Experimental Research in Audiovisual Translation - Cognition, Reception, Production. On-line at http://www.jostrans.org/issue33/issue33 toc.php; last accessed 3 July 2020.

Dìaz Cintas, Jorge, Remael Aline, 2007. Audiovisual translation, subtitling. Manchester: St Jerome.

Fedriani, Chiara, Sansó, Andrea (Eds), 2017. Pragmatic Markers, Discourse Markers and Modal Particles: New perspectives. John Benjamins, Amsterdam/Philadelphia.

Fraser, Bruce, 2015. The combining of Discourse Markers - A beginning. Journal of Pragmatics 86, 48-53.

Freddi, Maria, Malagori, Chiara, 2014. Discourse markers in audiovisual translation. In: Maiorani, A. and Christie, C. (Eds.) Multimodal Epistemologies: Towards an Integrated Framework. Routledge, London, pp.191-209.

Furkó, Péter B., 2020. Discourse markers and beyond: Descriptive and critical perspectives on discourse-pragmatic devices across genres and languages. Palgrave Macmillan.

Gambier, Yves, Ramos Pinto, Sara (Eds), 2016. Audiovisual Translation: Theoretical and methodological challenges. Target 28(2).

Ghia, Elisa, 2019, (Dis)aligning across different linguacultures: Pragmatic questions from original to dubbed film dialogue. Multilingua 38(5), 583-600.

Guillot, Marie-Noëlle, 2010. Films subtitles from a cross-cultural pragmatics perspective: Issues of linguistic and cultural representation. The Translator 16(1). 67-92.

Guillot, Marie-Noëlle, 2011. Issues of L2 pragmatic discrimination from an interactional perspective: The case of mais as a turn-initial device in L2 French. In: Béal, C., Auger, N., Demougin, F. Les Enjeux de la communication interculturelle, Maison des Sciences de l'Homme de Montpellier, Montpellier, pp.223-53.

Guillot, Marie-Noëlle, 2016a. Cross-cultural pragmatics and audiovisual translation. Target 28(2), 288-30.

Guillot, Marie-Noëlle, 2016b. Communicative rituals and audiovisual translation representation of otherness in film subtitles. META 61(3), 606-628.

Guillot, Marie-Noëlle, 2019. Subtitling's cross-cultural expressivity put to the test: A cross-sectional study of linguistic and cultural representation across Romance 
and Germanic languages. Multilingua 38(5) Special Issue: Audiovisual

Translation as intercultural mediation, pp.505-528.

Guillot, Marie-Noëlle, Pavesi, Maria, 2019. AVT as intercultural mediation. Multilingua 38(5), 495-504.

Guillot, Marie-Noëlle, Pavesi, Maria, Desilla, Louisa (Eds) 2019. Multilingua 38(5) Special Issue: Audiovisual translation as intercultural mediation.

Haselow, Alexander, 2019. Discourse marker sequences: Insights into the serial order of communicative tasks in real-time turn production. Journal of Pragmatics 146, 1-18.

Herbst, Thomas, 1997. Dubbing and the dubbed text: Style and cohesion. In: Trosborg, A. (Ed.) Text Typology and Translation. John Benjamins Amserdam/Philadlephia, pp.291-308.

Locher, Miriam, Jucker, Andreas (Eds), 2017. De Gruyter Handbooks of pragmatics: Pragmatics of fiction. Mouton de Gruyter. Berlin.

Meister, Lova, 2016. The T/V dilemma: Forms of address as a stylistic resource in English-Swedish subtitling. Perspectives, 24(4), 527-542.

Messerli, Thomas, 2017. Participation structure in fictional discourse. In Locher M. and Jucker A. (Eds.) De Gruyter Handbooks of Pragmatics: Pragmatics of Fiction. Mouton de Gruyter, Berlin, pp.25-54

Messerli, Thomas, 2019. Subtitles and cinematic meaning-making: Interlingual subtiltes as textual agents. Multilingua 38(5), 529-546.

Molés-Cases, Teresa, 2019. Why typology matters: a corpus-based study of explicitation and implicitation of Manner-of-motion in narrative texts. Perspectives, 27(6), 890-907.

Munday, Jeremy, 2018. A model of appraisal: Spanish interpretations of President Trump's inaugural address 2017. Perspectives 26(2), 180-195.

de Pablos-Ortega, Carlos, 2019 "I'm so sorry to disturb you but I wonder if I could have your autograph" versus "¿Me firma un autógrafo por favor?" Contrastive (In)Directeness in Subtitling. In: Tipton R. and Desilla L. (Eds) The Routledge Handbook of Translation and Pragmatics. Routledge, London, pp.205-224.

Pavesi, Maria, 2008. Spoken language in film dubbing: Target language norms, interference and translational routines. In: Chiaro, D, Heiss, C., Bucaria, C. (Eds) Between Text and Image: Updating research in screen translation. John Benjamins, Amsterdam/Philadelphia, pp.79-99.

Pavesi, Maria, 2012. The Enriching Functions of Address Shifts in Film Translation. In: Carroll, M., Orero, P., Remael, A. Audiovisual Translation and Media Accessibility at the Crossroads. Rodopi, Amsterdam, pp.335-356.

Pavesi, Maria, Formentelli, Maicol, 2019. Comparing Insults across languages in films: Dubbing as cross-cultural mediation, Multilingua 38 (5), 63-582.

Pérez-González, Luis, 2007. Appraising dubbed conversation: Systemic functional insights into the construal of naturalness in translated film dialogue. The Translator 13(1), 138.

Pérez-González, Luis (Ed.), 2018. The Routledge Handbook of Audiovisual Translation. Routledge, London.

Ranzato, Irene, Zanotti, Serenella (Eds), 2018. Linguistic and Cultural Representation in Audiovisual Translation. London: Routledge.

Remael, Aline, 2003. Mainstream narrative film dialogue and subtitling: A case study of Mike Leigh's Secrets \& Lies (1996). The Translator 9(2), 225-247.

Romero Fresco, Pablo, 2009. Naturalness in the Spanish dubbing language: A case of not-so-close Friends. META 54(1), 49-72. 
Schiffrin, Deborah, 1987. Discourse Markers. Cambridge University Press, Cambridge.

Sidiropoulou, Maria, 2013. Representation through translation: Shared maps of pragmatic meaning and the constructionist paradigm. Journal of Pragmatics 53, 96-108.

Tipton, Rebecca, Desilla, Louisa (Eds), 2018. The Routledge Handbook of Translation and Pragmatics. Routledge, London.

Valdeón, Roberto, 2008. Inserts in modern-script writing and their translation into Spanish. In: Chiaro, D., Heiss, C., Bucaria, C. (Eds) Between Text and Image: Updating research in screen translation. John Benjamins, Amsterdam/Philadelphia, pp.117-132. 